\title{
Fetal thyroid hyperplasia, rhesus isoimmunisation, and amniography
}

\author{
D M O BECROFT, W M I SMEETON, AND J H STEWART
}

\begin{abstract}
Department of Pathology, and Department of Radiology, The National Women's Hospital, Auckland, New Zealand
\end{abstract}

SUMMARY Thyroid hyperplasia was identified at necropsy in 16 of 70 cases of haemolytic disease of the newborn due to rhesus isoimmunisation dying in the years 1959-76. No hyperplasia was found in the thyroids from 140 nonrhesus-affected infants matched for date of birth, bodyweight and length, and gestation, or in cases of haemolytic disease born before 1966. All 16 infants with thyroid hyperplasia had received intrauterine transfusions and the iodine-containing contrast media used for preliminary amniography were the only goitrogenic factors identified. Lipiodol, first used in 1966, was considered to have the greatest effect. The 16 infants with hyperplastic thyroids were less mature and smaller than 22 infants with normal thyroids who had been similarly exposed to contrast media. The high incidence of hyperplasia may be due to immaturity of the adaptive mechanisms which allow most normal individuals to escape the goitrogenic effects of iodine compounds.

In a preliminary report in 1976 we described the finding of hyperplasia of the thyroid glands in some infants with haemolytic disease due to rhesus isoimmunisation. ${ }^{1}$ Thyroid hyperplasia had not previously been described in association with this disease. All infants had received intrauterine transfusions, a procedure introduced by Liley at the National Women's Hospital in 1963. ${ }^{2}$ We suggested that the use of iodine-containing contrast medium for preliminary amniography (amniofetography) was the likely cause of the thyroid abnormality, although there were many other similarly treated infants with normal thyroids. We have made a more detailed study of infants with haemolytic disease dying at the same hospital between 1959 and 1976.

\section{Material and methods}

We reviewed the histology of the thyroid glands of 334 rhesus-affected infants examined at necropsy at the National Women's Hospital between January 1959 and April 1976. The majority were stillbirths in whom tissues were autolysed, but histological

\footnotetext{
Princess Mary Hospital for Children, Auckland

D M O BECROFT, pathologist

Department of Pathology, School of Medicine, University of Auckland

W M I SMEETON, senior lecturer

National Women's Hospital, Auckland

J H STEWART, radiologist
}

interpretation was possible in glands from 70 cases. A control series of sections of thyroid glands from 140 nonrhesus-affected infants was then obtained, 2 from each of the 70, matched for gestation $( \pm 1$ week) and crown to heel length $( \pm 2 \mathrm{~cm})$, these being the next 2 liveborn or stillborn infants with wellpreserved glands, by name in alphabetical order, of necropsies for each year. The sections of all 210 thyroid glands were coded and examined 'blind'. Clinical and radiological records and the remaining histopathological material from the 70 rhesusaffected infants were then reviewed.

\section{Results}

Histology of 210 thyroid glands. 194 thyroids were assessed as normal for gestation and these were found to include all $\mathbf{1 4 0}$ glands from control infants. Thyroid follicles varied in size but most of them were round, filled with pale-staining colloid, and lined by cuboidal or flattened cells with uniform nuclei and little cytoplasm (Fig. 1a). 16 glands, all from rhesusaffected infants, showed hyperplasia (Fig. $1 \mathrm{~b}$ and $\mathrm{c}$ ). Follicles had variable sizes and irregular shapes, and the lining cells were columnar, many had hyperchromatic nuclei or were dividing. There were many intrafollicular papillary projections. Colloid was either absent or much diminished. The change was diffuse and there was no nodule formation or inflammatory cell reaction. Some of the 


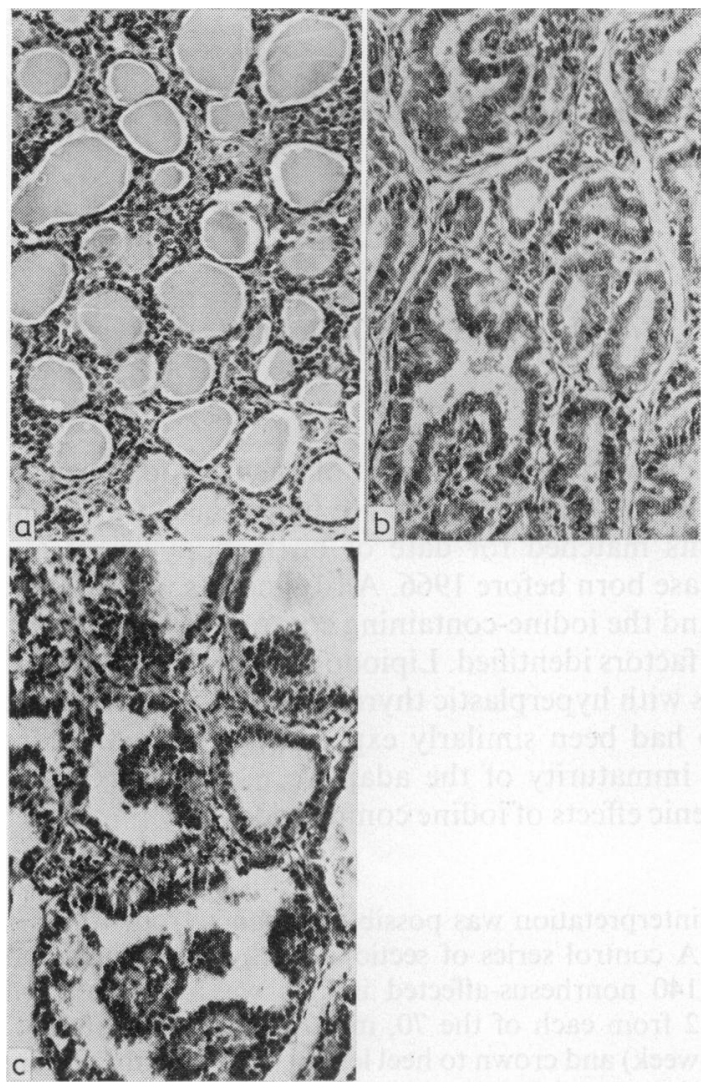

Fig. 1 Photomicrographs of histological sections of (a) a normal neonatal thyroid gland and, (b) and (c) hyperplastic glands from rhesus-affected infants after amniography $\times 100$.

hyperplastic glands had been visibly enlarged. Latterly, glands were weighed and in Fig. 2 the weights of 5 hyperplastic glands are compared with those from 40 nonrhesus-affected infants.

Because thyroid hyperplasia had been found only in cases of rhesus isoimmunisation, further study was restricted to the latter disease.

Analysis of 70 rhesus-affected infants. The hyperplastic glands were from $16(40 \%)$ of 40 infants born after 1965 and no hyperplasia was found in 30 infants born earlier (Fig. 3). All infants examined in 1974-76 had hyperplastic glands.

Other data on the infants with and without thyroid hyperplasia are presented in the Table. Infants with hyperplastic glands were of lesser median gestation and body size; there was an unexplained male predominance among those with normal glands; other differences were insignificant.

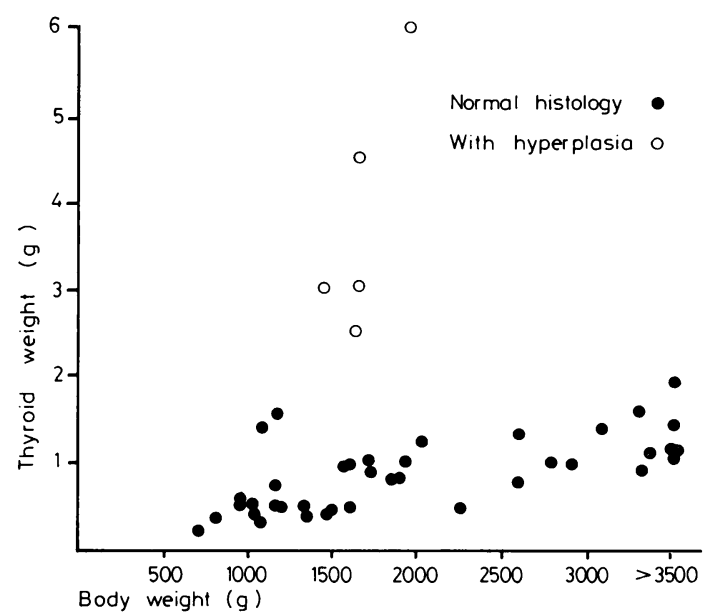

Fig. 2 Weights of thyroid glands at necropsy, each related to body weight, of 5 rhesus-affected infants in which thyroid hyperplasia was identified and of 39 randomly selected nonrhesus-affected infants with normal thyroid histology.

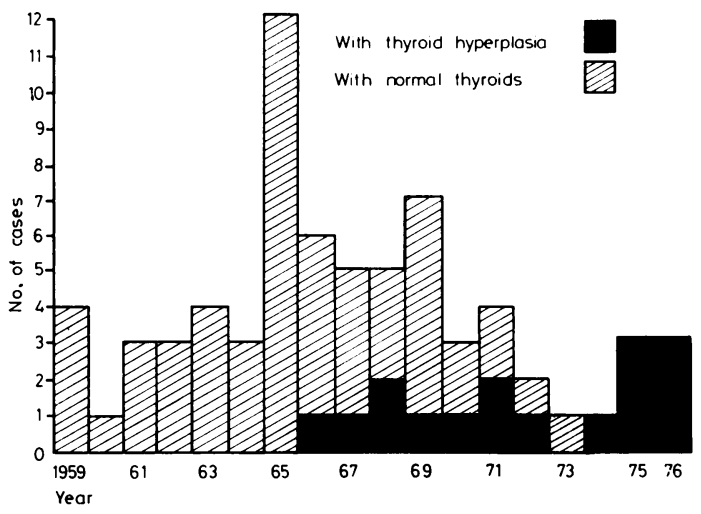

Fig. 3 Incidence of thyroid hyperplasia in 70 infants with haemolytic disease of the newborn dying between 1959 and 1976.

Three possible reasons for thyroid hyperplasia were investigated.

Maternal factors unrelated to rhesus isoimmunisation There was no history of thyroid disease or treatment for thyroid disease in mothers of infants both with and without thyroid hyperplasia. No drugs with known effects on thyroid function had been given to mothers in either group. Several drugs had been given more often to the mothers of the infants with thyroid hyperplasia but none was common to all. The most common was ampicillin, given prophylactically after amniocentesis to 11 mothers. 
Severity of haemolytic disease

All 16 infants with hyperplastic thyroids had received intrauterine transfusions because their haemolytic disease was severe. In comparison 15 of the 40 infants without thyroid hyperplasia received intrauterine transfusions. 16 others had cord blood $\mathrm{Hb}<8.0 \mathrm{~g} / \mathrm{dl}$ and therefore were severely affected, although for various reasons they did not have intrauterine transfusions.

The pathological findings in other organs of the 16 infants with hyperplastic thyroids were those expected in severe haemolytic disease which had been modified by intrauterine transfusions-that is, a variable severity of subcutaneous oedema, effusions into serous cavities, visceral and intravascular erythroblastosis, hepatic and splenic haemosiderosis, lipid accumulation in the fetal adrenal cortex, and placental oedema. However, equally severe changes were found in a larger number of infants who had normal thyroids. Eight infants with thyroid hyperplasia had hyperplastic islets of Langerhans, but this change was also found in 12 infants with normal thyroids. Sections of pituitary glands were available from 5 infants with hyperplastic thyroids and no differences were detected between these and pituitaries from rhesus-affected infants with normal thyroids.

\section{Management of haemolytic disease}

All infants with hyperplastic thyroids had received at least one intrauterine transfusion. The blood transfused is unlikely to have affected thyroid function in all cases, whereas the associated radiological procedures provide a very likely explanation. The practice at the National Women's Hospital ${ }^{3}$ is to perform amniography at the first diagnostic amniocentesis with, according to the size of the fetus, 3 to $6 \mathrm{ml}$ of iodised oil (Lipiodol Ultra-fluid,* containing 37 to $39 \%$ by weight of combined

* May and Baker Ltd. iodine) mixed with 12 to $20 \mathrm{ml}$ of water-soluble contrast medium $(76 \%$ Urografin, $\nmid$ containing $37 \%$ iodine by weight). At the later intrauterine transfusion at least $2 \mathrm{ml}$ Urografin was injected into the fetal peritoneal cavity to help in the localisation of the catheter. Urografin alone was used for the preliminary amniography before 1966. Further intraperitoneal Urografin was given at subsequent transfusions, but additional intra-amniotic contrast medium rarely was required.

Information on the use of contrast media was available for 68 of the 70 cases. All 16 infants with hyperplastic thyroids had been exposed to contrast media in utero compared with 22 infants exposed among $\mathbf{5 2}$ with normal thyroids, a difference unlikely to have occurred by chance $(P<0.025)$. All infants with hyperplastic thyroids had been exposed to Urografin, but with one exception there was a record that this had been in combination with Lipiodol. Thus, only one of 10 infants apparently exposed to Urografin alone showed thyroid hyperplasia, compared with 15 cases with hyperplasia from 28 infants exposed to both Lipiodol and Urografin, a highly significant difference $(\mathrm{P}<0.003)$ which indicates that the addition of Lipiodol had a major effect.

The reason why only some infants exposed to contrast media were affected was then considered.

Analysis of 38 infants exposed to contrast media. The 16 infants with hyperplastic thyroids were compared with the 22 with normal thyroids who had also been exposed to contrast media in utero (Table).

\section{Severity of disease}

As expected in cases requiring treatment by intrauterine transfusions, all had the pathological † Schering Chemicals Ltd.

Table Data on 70 infants with haemolytic disease due to rhesus isoimmunisation

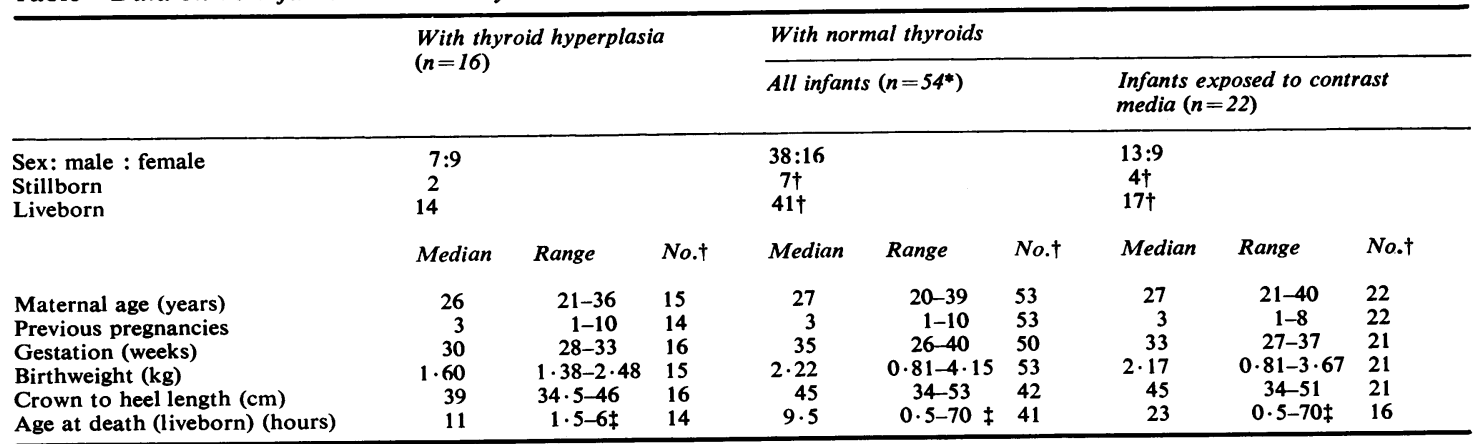

*Includes one set of twins, $\uparrow$ number with reliable information, fupper limit in days. 
features of severe disease and there were no differences between the two groups.

\section{Maturity and size of infants}

The infants with hyperplastic thyroids were born at significantly shorter gestations than those with normal thyroids $(P<0 \cdot 05)$ and had correspondingly lower weights and crown to heel lengths.

\section{Number of transfusions}

The number of intrauterine transfusions ranged from 1 to 5 . A mean of 1.8 transfusions had been given to the 13 cases with hyperplastic thyroids in which this information was reliably recorded, compared with a mean of $2 \cdot 5$ transfusions given to 15 infants who had normal thyroids.

\section{Dose of contrast media}

Although intra-amniotic and intraperitoneal doses were within the ranges previously quoted, the exact amounts were often not stated and total doses in the two groups could not be compared. In the single example of hyperplasia believed to follow the use of Urografin only, the dose of $42 \mathrm{ml}$ was the largest recorded.

\section{Absorption and dispersal of media}

There was insufficient radiological data to allow comparison of fetal swallowing and other dispersal of media in the two groups.

\section{Duration of exposure}

In 12 infants who had thyroid hyperplasia after Lipiodol and Urografin had been used in combination, the median interval between the first amniogram and delivery was 19 days (range 4-70), little different from the median of 20 days (range 3-96) for 12 infants with normal thyroids. Delivery was 20 days after the first amniogram in the single case with hyperplasia after Urografin alone, compared with a median of 16 days (range 2-30) in 9 infants without hyperplasia after Urografin alone.

\section{Discussion}

The only constant association found on review of these cases of thyroid hyperplasia and rhesus isoimmunisation was that their severe haemolytic disease required treatment by intrauterine transfusions. The thyroid hyperplasia is unlikely to be a further manifestation of the endocrine abnormalities found in severe haemolytic disease because it was absent in an even larger number of severely affected infants, and it was not observed in affected infants before 1966. A relationship to a change in medical management occurring about 1966 appears more likely. The only change identified was the introduction of Lipiodol Ultra-fluid into amniography, and the coincidence reinforces the likelihood that the hyperplasia was caused by the goitrogenic effect of iodine released from the contrast medium and absorbed either from the fetal gut or perhaps from the skin. ${ }^{4}$

There have been many reports of the induction of congenital goitre by iodine-containing compounds, and hypothyroidism has been identified in some surviving infants. Wolff ${ }^{5}$ reviewed 25 cases of congenital goitre due to maternal ingestion of inorganic or organic iodine compounds and other reports of substantial numbers of similar cases have continued. ${ }^{6-7}$ Wolff $^{5}$ noted the high incidence of histological hyperplasia in iodine-induced goitres in the newborn, but his suggestion that this might occur frequently at this age from other causes is not borne out by the control series of the study, or by our experience of neonatal thyroid histology in general. Iodides, above a critical dose, inhibit hormone formation in the thyroid glands of man and animals, the Wolff-Chaikoff effect, the mechanism of which remains uncertain. ${ }^{8}$ If the effect is prolonged, thyroid enlargement develops because of stimulation by pituitary thyroid-stimulating hormone (TSH). The effect appears to be rapid because the least degree of histological abnormality detected in our survey was in an infant dying only 4 days after amniography.

Other studies of thyroid function in newborn infants after amniography support our observation that Lipiodol has a much greater effect than watersoluble contrast media. Rodesch et al. ${ }^{9}$ who used $12 \mathrm{ml}$ Lipiodol and $30 \mathrm{ml}$ meglumine diatrizoate (Angiografin) found that 6 of 7 infants exhibited a pronounced increase in serum TSH levels on the 5th day of life, and in 2 cases hypothyroidism of short duration was confirmed by the association of increased TSH levels with decreased T4 levels. In contrast Morrison et al. ${ }^{10}$ found no abnormality of the levels of serum T4 and T3-resin-uptake in the cord bloods of 25 infants born after amniography with Urografin alone. Ranke et al. ${ }^{11}$ described goitre and hypothyroidism in an infant born 3 weeks after amniography with Lipiodol and a watersoluble contrast medium. Two other cases of neonatal hypothyroidism were reported after accidental injection of contrast media, including Lipiodol, into the fetal subcutaneous tissues during amniography. ${ }^{12}$ The greater effect of Lipiodol is most likely due to its persistence in the amniotic cavity and on the fetal skin until birth, providing continuous exposure to iodide, whereas watersoluble media are cleared rapidly. Other factors which might be contributory are greater instability 
leading to release of more free iodine, greater absorption, with or without degradation in the fetal intestine, and differing rates of clearance from the fetal circulation by the placenta.

The absence of thyroid hyperplasia in other infants who were exposed to Lipiodol and Urografin for a similar time may be due to the well-known individual variability in responsiveness to iodine. The mechanism of the usual rapid 'escape or adaption' of hormone secretion from the inhibitory effects of excess iodide is poorly understood, ${ }^{8}$ but it is associated with a decrease in iodide transport into the gland. The failure of a minority of individuals to show such adaption is in part geneticallydetermined, ${ }^{13}$ but genetic factors alone are unlikely to have determined the hyperplastic response found in $40 \%$ of the infants born between 1966 and 1975 . Glands stimulated by TSH are more sensitive to the Wolff-Chaikoff effect, and blood TSH levels are high during the latter half of pregnancy. ${ }^{14}$ Immaturity of the adaptive response is another possible explanation which is supported by the lesser gestations of those infants who did have a hyperplastic response. The alternative explanation, that the smaller size of these infants was a reflection of a greater dose of contrast medium relative to body weight, could not be examined in detail because of lack of data on the quantities of contrast media used. Since, on average, the infants with normal thyroids received more transfusions than those with hyperplasia a doserelated effect is unlikely, but the number of transfusions is irrelevant if Lipiodol is the major factor and is given only at the first transfusion. All thyroid glands studied in the years 1974-76 were hyperplastic, causing suspicion of a high free-iodine content of batches of media in use at that time, but no further information could be obtained.

Although histological changes were impressive, the enlargement of the thyroid glands of our cases was slight in comparison with the massive goitres which have developed after prolonged maternal ingestion of iodides, and there was none of the anatomical consequences of such enlargement. The consequences of hypothyroidism, however transient, are more difficult to assess. The deaths of all infants were adequately accounted for by the severity of their haemolytic disease or the effects of prematurity. Nevertheless, hypothyroidism would suppress bilirubin conjugation in surviving infants and the effects on the nervous system and other developmental processes are unpredictable. Amniofetography with Lipiodol provides valuable information for the management of severe haemolytic disease and in other clinical situations, but a further assessment of the consequences on thyroid function is necessary before the procedure can be regarded as without harmful effects on the fetus.

\section{References}

1 Becroft D M O, Stewart J H, Smeeton W M I. Letter: Rhesus sensitisation, amniography, and thyroid hyperplasia. Lancet 1976; 2: 1191-2.

2 Liley A W. Intrauterine transfusion of foetus in haemolytic disease. $\mathrm{Br}$ Med J 1963; ii : 1107-9.

${ }^{3}$ Stewart J H. Further observations on the radiology of intrauterine foetal blood transfusions. Australas Radiol 1969; 13: 205-10.

4 Chabrolle J P, Rossier A. Goitre and hypothyroidism in the newborn after cutaneous absorption of iodine. Arch Dis Child 1978; 53: 495-8.

5 Wolff $\mathbf{J}$. Iodide goiter and the pharmacologic effects of excess iodide. Am J Med 1969; 47: 101-24.

- Carswell F, Kerr M M, Hutchison J H. Congenital goitre and hypothyroidism produced by maternal ingestion of iodides. Lancet 1970; 1 : 1241-3.

7 Job J C, Bocquentin F, Canlorbe P. Les goitres du nouveau-né. Arch Fr Pediatr 1974; 31 : 127-36.

8 Vagenakis A G, Braverman L E. Adverse effects of iodides on thyroid function. Med Clin North Am 1975; 59: 1075-88.

- Rodesch F, Camus M, Ermans A M, Dodion J, Delange F. Adverse effect of amniofetography on fetal thyroid function. Am J Obstet Gynecol 1976; 126: 723-6.

10 Morrison J C, Boyd M, Friedman B I, et al. Effects of Renografin-60 on the fetal thyroid. Obstet Gynecol 1973; 42: 99-1.03.

11 Ranke M, Nothjunge J, Mentzel H. Kongenitale Struma bei einem Frühgeborenen nach Amniographie. Monatsschr Kinderheilkd 1977; 125: 941-3.

12 Denavit M-F, Lecointre $\mathrm{Cl}$, Mallet $\mathrm{E}$, de Ménibus $\mathrm{Cl}$, Rossier A. Un accident de l'amniofoetographie: l'hypothyroìdie. Arch Fr Pediatr 1977; 34: 543-51.

13 Croughs W, Visser H K A. Familial iodide-induced goitre. Evidence for an abnormality in the pituitarythyroid homeostatic control. J Pediatr 1965 ; 67: 353-62.

14 Fisher D A, Hobel C J, Garza R, Pierce C A. Thyroid function in the pre-term fetus. Pediatrics $1970 ; 46: 208-16$.

Correspondence to Dr D M O Becroft, Princess Mary Laboratory, Auckland Hospital, Park Road, Grafton, Auckland 1, New Zealand.

Received 5 December 1978 